\title{
An Innovative Modelling Approach Based on Building Physics and Machine Learning for the Prediction of Indoor Thermal Comfort in an Office Building ${ }^{\dagger}$
}

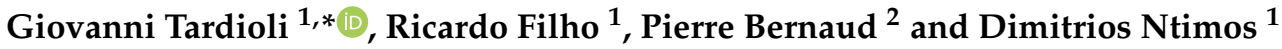 \\ 1 Integrated Environmental Solutions R\&D Ireland, 1 Dublin, Ireland; ricardo.filho@iesve.com (R.F.); \\ dimitrios.ntimos@iesve.com (D.N.) \\ 2 CEA/LITEN_Department of Solar Energy, 73370 Le Bourget-du-Lac, France; pierre.bernaud@cea.fr \\ * Correspondence: giovanni.tardioli@iesve.com \\ † Presented at the Sustainable Places 2021, Rome, Italy, 29 September-1 October 2021.
}

Citation: Tardioli, G.; Filho, R.;

Bernaud, P.; Ntimos, D. An

Innovative Modelling Approach Based on Building Physics and Machine Learning for the Prediction of Indoor Thermal Comfort in an Office Building. Environ. Sci. Proc. 2021, 11, 25. https://doi.org/ 10.3390/environsciproc2021011025

Academic Editor: Zia Lennard

Published: 2 December 2021

Publisher's Note: MDPI stays neutral with regard to jurisdictional claims in published maps and institutional affiliations.

Copyright: (c) 2021 by the authors. Licensee MDPI, Basel, Switzerland. This article is an open access article distributed under the terms and conditions of the Creative Commons Attribution (CC BY) license (https:/ / creativecommons.org/licenses/by/ $4.0 /)$.

\begin{abstract}
In this paper, an innovative hybrid modelling technique based on machine learning and building dynamic simulation is presented for the prediction of indoor thermal comfort feedback from occupants in an office building in Le Bourget-du-Lac, Chambéry, France. The office was equipped with Internet of Things (IoT) environmental sensors. A calibrated building energy model was created for the building using optimisation tools. Thermal comfort was collected using a portable device. A machine learning (ML) model was trained using collected feedback, environmental data from IoT devices and synthetic datasets (virtual sensors) extracted from a physics-based model. A calibrated energy model was used in co-simulation with the predictive method to estimate comfort levels for the building. The results show the ability of the method to improve the prediction of occupant feedback when compared to traditional thermal comfort approaches of about $25 \%$, the importance of information extracted from the physics-based model and the possibility of leveraging scenario evaluation capabilities of the dynamic simulation model for control purposes.
\end{abstract}

Keywords: building physics model; machine learning; thermal comfort; hybrid modelling; datadriven; occupant feedback

\section{Introduction}

The prediction of indoor environmental quality levels in office buildings is important for the provision of satisfactory and safe work environments and for the enhancement of the productivity of personnel and reductions in complaints [1]. Achieving a holistic control over Indoor Environmental quality (IEQ) and thermal comfort in particular is difficult as it requires advanced capabilities to evaluate current and future conditions for the occupants and how they interact with the environment [2]. The increase in available data from buildings, as well as the wide spread of digital representation of built environment (digital twins), is producing a substantial amount of data that can be used for current and future estimations of IEQ levels [3]. Current thermal comfort techniques have shown shortcomings when compared to actual feedback from occupants regarding comfort. For example, traditional calculation methods such as the predicted mean vote (PMV) and the adaptive thermal comfort (EN 16798 and ASHRAE 55) reached limited accuracy when compared to feedback from occupants [4]. New methods based on data-driven solutions, in particular machine learning (ML), showed the ability to learn complex interactions among data, surpassing current comfort calculation methods [5]. Some environmental variables useful for the training of machine learning methods are difficult and expensive to measure by sensors (e.g., operative temperature, mean radiant temperature, and surface temperature) [6]. Digital twins intended as calibrated building energy models cover a fundamental role in generating an accurate representation of the building environment by creating 
digital versions of the actual buildings [7]. In this work, the calibrated building energy models are used as a source of virtual variables data that are used to enhance the predictive capability of machine learning and, at the same time, as a source of data regarding different operational scenarios of the building. This work contributes to the current literature by focusing on three main objectives: (1) testing the capabilities of ML models when used for predicting thermal comfort votes of occupants; (2) combining the use of ML models for thermal comfort evaluation with physics dynamic simulation in a co-simulation environment to generate dynamic predictions of relevant metrics; (3) establishing a comparison with traditional normative methods of evaluating thermal comfort.

\section{Materials and Methods}

The methodology used was based on the combination of data-driven methods and building dynamics simulation, as shown in Figure 1.

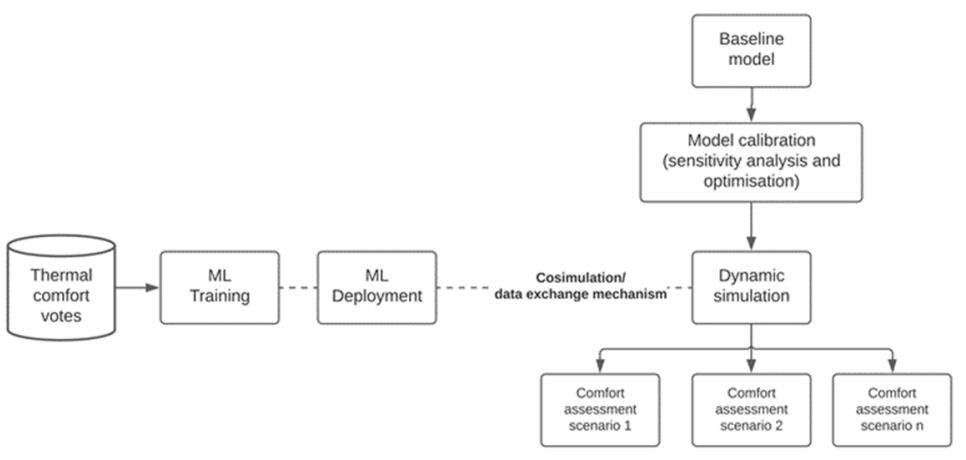

Figure 1. Methodology diagram.

First, relevant comfort-related data were collected by setting up an occupant comfort experiment in the building case study and installing a network of IoT sensors to gather relevant environmental information. A portable device was used to gather feedback regarding thermal comfort in the building. A baseline energy model of the building was generated, and a calibration procedure was performed. This was achieved by gathering building data, by leveraging data analysis of time series from meters and IoT sensors in the building for the generation of tailored operational profiles, and by using optimization techniques for the fine-tuning of important modelling parameters. Several machine learning models were trained, and their predictions were evaluated in comparison to the available thermal comfort data. In particular, a Bayesian multilinear regression model was trained on the available comfort data, environmental variables from the IoT, and virtual sensors extracted from the calibrated model. The calibrated model was used: (i) to gather additional virtual sensor variables to extend the set of predictors for the ML model; and (ii) as source of information in a co-simulation environment to exchange data with the ML model for thermal comfort predictions. In this context, the scenario evaluation capabilities of the physics-based simulation model was used as a data generation method for operational scenarios of the building that was processed by the ML model to predict effects on the thermal comfort.

\section{Results}

The research methodology described in Section 2 was applied to the Helios building research centre in Le Bourget-du-Lac, France, where a comfort experiment was performed in 2018 with a focus on the summer months and then extended over an entire year until June 2019. Figure 2 shows the feedback app used during the comfort experiment (left) and the baseline building energy model (right). Figure 3 depicts the results of the calibration process with the comparison of the baseline calibrated model and the optimized one (left) The graph on the right in the same image shows the temperature timeseries output of the simulation and the actual temperature data gathered from the IoT devices. Figure 4 shows 
the results of the validation of the Bayesian multilinear regression model under different error acceptance ranges. Figure 5 shows the results of the comparison between the actual votes from the occupants (extrapolated), the PMV method, and the prediction of the ML method (Bayesian multilinear regression model).
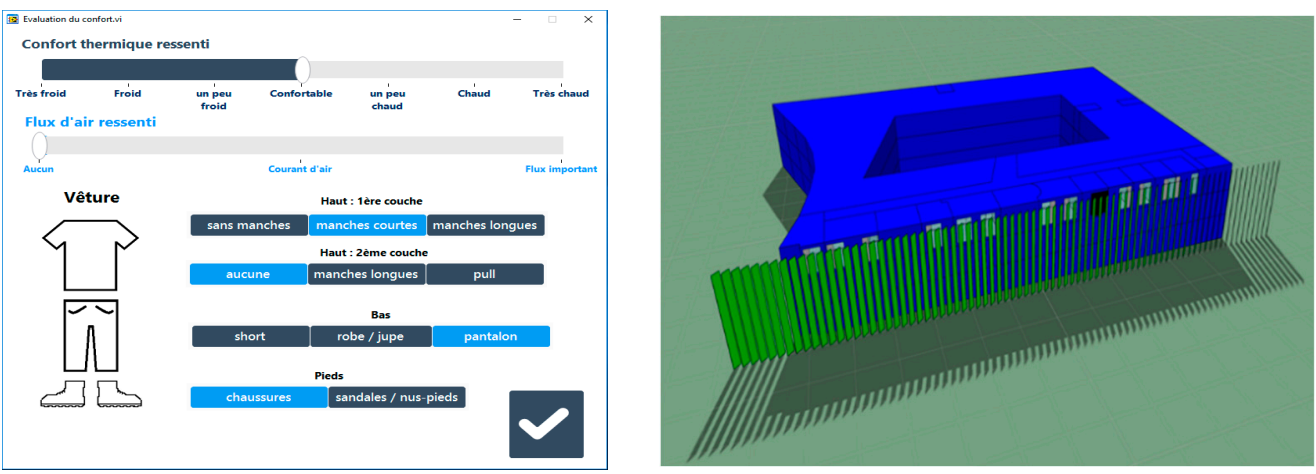

Figure 2. View of the feedback app display (left). IESVE building energy model (right).
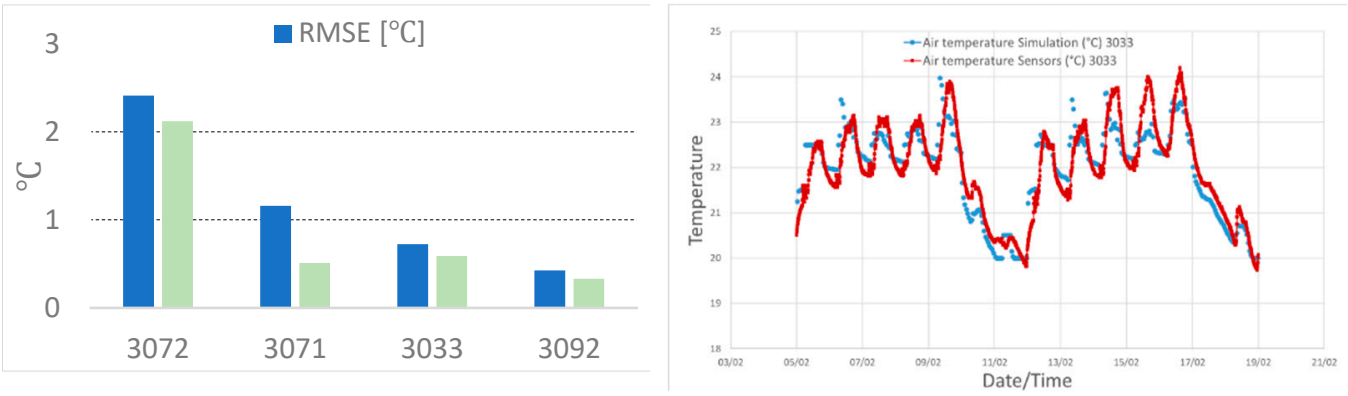

Figure 3. Root mean squared error for air temperature: comparison calibrated model vs. optimised model (left). Comparison of air temperature measurements and output of the simulation (right).

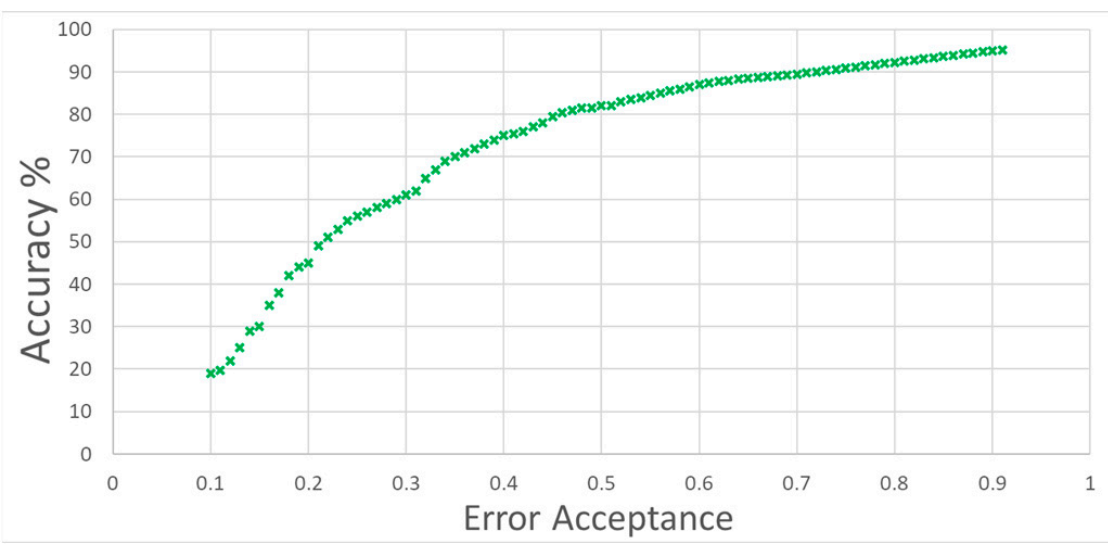

Figure 4. Accuracy of the Bayesian multi-linear regression model for thermal comfort predictions. 


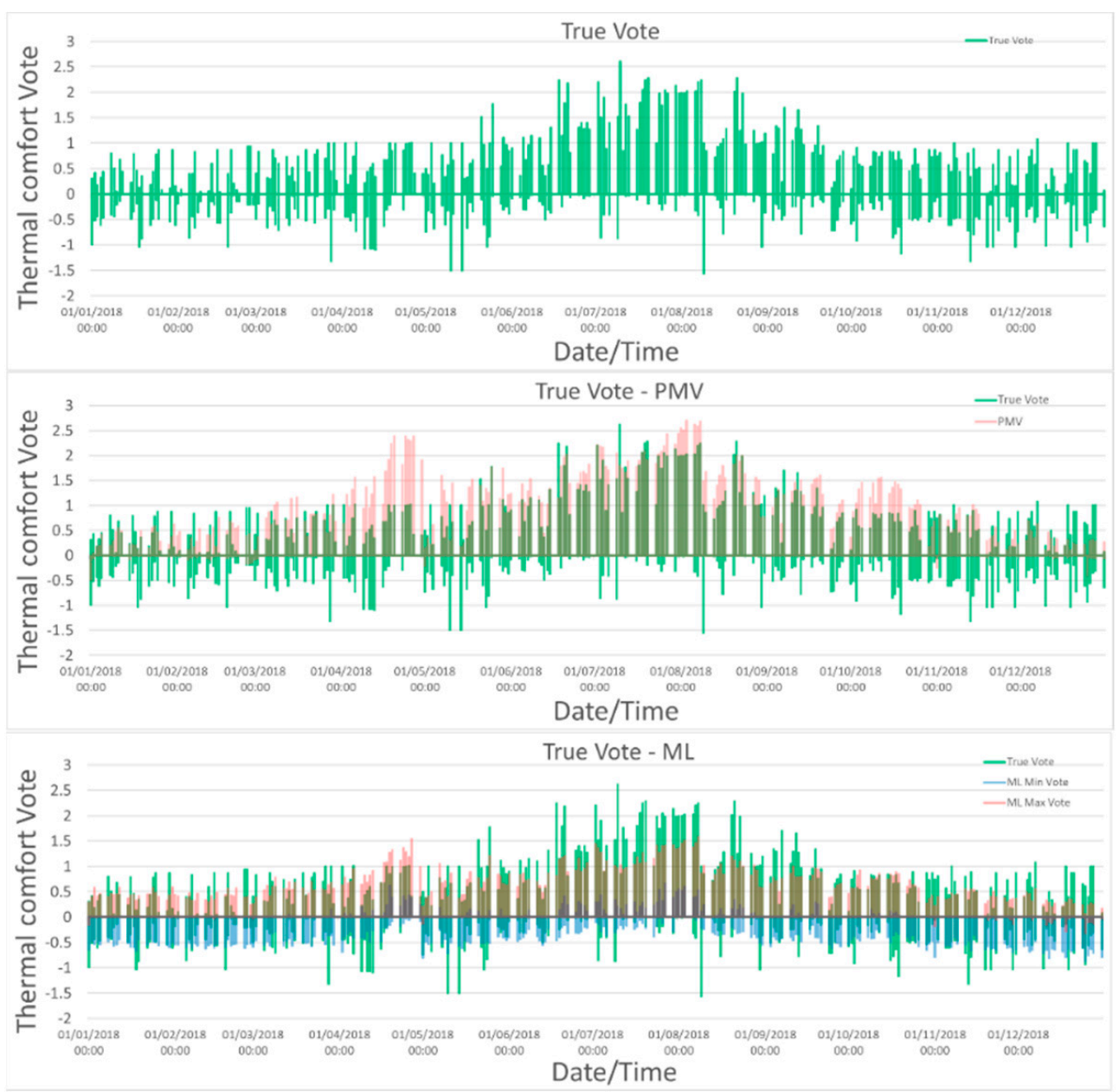

Figure 5. Comparison between the true comfort feedback, the PMV evaluation and the ML model results.

\section{Discussions and Conclusions}

The results of the model calibration show that a multi-step methodology and continuous data gathering and integration from the real building allows for the evolution of the baseline model over time, to an operational and finally to an optimized model. The use of data analysis for the creation of schedules of operations at the building and system levels allows for a more accurate representation of the actual operations of the building. The automatic fine-tuning procedure through optimization further shortens the gap between the real building and the simulated one. Validation tests show that the final model is fully capable of reproducing the thermal behaviour of the real building with regard to IEQ variables. The results show that ML algorithms, when compared to normative approaches such as the PMV method, reduce the prediction error by at least $25 \%$, reaching a highest accuracy of almost $70 \%$ on a 7 -value scale and about $85 \%$ on a 3 -value scale. The use of Bayesian modelling allowed for a more realistic response in terms of possible ranges of thermal comfort with minimum and maximum limits of acceptability and for the possibility of predicting values on a continuous scale. It was possible to extract additional information for the training of the ML algorithms such as the mean radiant temperature by leveraging the physics-based model. In conclusion, this work shows that by merging building physics modelling to machine learning techniques, it is possible to create a hybrid modelling approach which showed several advantages and is able to overcome the limitations of traditional thermal comfort models for office buildings. The hybrid approach can be further leveraged to create tailored predictive models for testing building control routines, as well as optimised operational scenarios, before being applied on an actual building. 
Author Contributions: Conceptualization, G.T.; methodology, G.T.; software, G.T.; validation, G.T. and R.F.; formal analysis, G.T. and R.F.; investigation, G.T. and R.F.; resources, D.N.; data curation, G.T. and R.F; writing-original draft preparation, G.T.; writing-review and editing, G.T., D.N. and P.B.; visualization, G.T.; supervision, D.N. and P.B.; project administration, D.N.; funding acquisition, D.N. All authors have read and agreed to the published version of the manuscript.

Funding: This research was funded by the H2020 iBECOME project, grant number 894617.

Conflicts of Interest: The authors declare no conflict of interest.

\section{References}

1. Mallawaarachchi, H.; De Silva, L.; Rameezdeen, R. Modelling the relationship between green built environment and occupants' productivity. Facilities 2017, 35, 170-187. [CrossRef]

2. Larsen, T.S.; Rohde, L.; Jønsson, K.T.; Rasmussen, B.; Jensen, R.L.; Knudsen, H.N.; Witterseh, T.; Bekö, G. IEQ-Compass-A tool for holistic evaluation of potential indoor environmental quality. Build. Environ. 2020, 172, 106707. [CrossRef]

3. Al-Sehrawy, R.; Kumar, B. August. Digital twins in architecture, engineering, construction and operations. A brief review and analysis. In International Conference on Computing in Civil and Building Engineering; Springer: Cham, Switzerland, 2020; pp. 924-939.

4. Enescu, D. A review of thermal comfort models and indicators for indoor environments. Renew. Sustain. Energy Rev. 2017, 79, 1353-1379. [CrossRef]

5. Luo, M.; Xie, J.; Yan, Y.; Ke, Z.; Yu, P.; Wang, Z.; Zhang, J. Comparing machine learning algorithms in predicting thermal sensation using ASHRAE Comfort Database II. Energy Build. 2020, 210, 109776. [CrossRef]

6. Aivaliotis, P.; Georgoulias, K.; Arkouli, Z.; Makris, S. Methodology for enabling digital twin using advanced physics-based modelling in predictive maintenance. Procedia CIRP 2019, 81, 417-422. [CrossRef]

7. Shahinmoghadam, M.; Natephra, W.; Motamedi, A. BIM-and IoT-based virtual reality tool for real-time thermal comfort assessment in building enclosures. Build. Environ. 2021, 199, 107905. [CrossRef] 